\title{
Additional Information Concerning 'Erratum to: Western Purple-Faced Langurs \\ (Semnopithecus vetulus nestor) Feed on Ripe and Ripening Fruit in Human-Modified Environments in Sri Lanka'
}

Published online: 29 July 2015

(C) Springer Science+Business Media New York 2015

\section{Position of the Author of the Original Paper}

Statement to Correct the Scientific Record Pertaining to the 'Erratum' to: Western Purple-Faced Langurs (Semnopithecus vetulus nestor) Feed on Ripe and Ripening Fruit in Human-Modified Environments in Sri Lanka' authored by Joanna M. Setchell

\section{Jinie D. S. Dela}

(Author of Dela 2007 and 2012).

I rebut the so called 'Erratum' which I find unwarranted, invalid, misleading and suppresses facts for the reasons explained below.

In the "Erratum", Dr. Setchell, handling editor and reviewer of my 2012 paper, claims she noticed partial redundancy (after its publication), as per COPE guidelines, due to "substantial" overlap with my 2007 paper, with only the "distinction between ripe or ripening fruits versus fruits eaten just for seeds" being new. Conversely, my 2012 paper does not conform to any publicly accepted definition of redundancy by Springer (Springer 2013), or COPE flowcharts/guidelines (i.e. "same data set with identical findings" or " "salami publishing' with some element of redundancy" or "legitimate re-analysis" - coupled with author/s hiding the first paper) (COPE 2013). Both papers were submitted to the IJP, differ in focus and analyses (confirmed in an

This comment refers to the articles available at doi:10.1007/s10764-011-9538-3, doi:10.1007/s10764-012-9628-x and doi:10. 1007/s10764-007-9150-8. 
independent opinion, David Vaux in Litt 2012), and the 2012 paper cites the 2007 paper 17 times in the Introduction, Methods and Discussion. These citations follow other second papers in the IJP sharing a dataset with previous papers (e.g. Davies et al. 1999; Li and Rogers 2006; Fashing et al. 2007). During the review, I revised the paragraph (content) linking the 2 papers as suggested by Dr. Setchell, and we both referred to the 2007 paper. Accordingly, as the IJP review process follows IJP reviewer guidelines (IJP n.d.)and COPE guidelines to editors (COPE 2011 item 4), "substantial" overlap between the two papers would have been revealed-had it existed.

Moreover, my 2007 paper presents feeding strategies of 2 langur groups to feed heavily on seasonal food (despite environmental differences), in a species known to subsist mainly on mature leaves. My 2012 paper builds on the high fruit use: “. . . both groups show high year-round use of seasonal food, composed mainly of fruit (Dela 2007), ..." to demonstrate high use of whole fleshy ripening/ripe fruit (despite availability of unripe fruit, edible leaves and seeds) and challenge the long-held argument that colobine monkeys avoided such fruit due to digestive adaptations for folivory. I provide new data on: vegetation; fruits used; use of whole fleshy ripe/ripening fruit vs unripe/non-fleshy fruit and seeds; selection of food species, plant parts and ripe/ ripening fleshy fruit; annual diet; etc. The Introduction, Discussion, Conclusions, Tables, Figures, hypotheses/predictions and analyses are new. Contrary to the Erratum: the 2007 data are not 're-analyzed with minor changes' ('salami slicing') as use of fruit sub-categories is the focus of my 2012 paper; Fig. 1 in Dela 2007 (relative density of plant species) is not split into Table 1 in Dela 2012 (plant families, Basal Area, IVI indices, etc); I never state the "study species" is "highly frugivorous" in either paper (most 'populations' are folivorous); Dela 2012 uses jakfruit to demonstrate feeding on ripe/ripening fleshy fruit, but cites Dela 2007 for jakfruit being the main fruit source ( $p$ 65); the 2007 paper never presents a frugivorous dietary strategy "unlike any other colobine" (several colobines show similar 'fruit' use); only the 2012 paper reveals frugivory "unlike any other colobine" (discussion) because of the study groups" continual high use of fleshy ripe/ripening whole fruit not reported for other colobines. 


\title{
Editor's Response
}

\author{
Dr. Joanna M. Setchell \\ Editor-in-Chief \\ International Journal of Primatology
}

The 'Erratum to: Western Purple-Faced Langurs (Semnopithecus vetulus nestor) Feed on Ripe and Ripening Fruit in Human-Modified Environments in Sri Lanka' (Setchell 2012), clarifies the relationship between two publications by Dr. Dela in this journal (Dela 2007, 2012). Since the publication of the Erratum, Dr. Dela and I have engaged in a lengthy and detailed email correspondence concerning the accuracy of its contents, mediated via the Committee on Publication Ethics (COPE). As Dr. Dela and I cannot reach agreement on the level of overlap between Dr. Dela's two publications, COPE suggested it would helpful to provide succinct additional information to readers. Dr. Dela has outlined her position in her statement. I stand by the contents of the Erratum, which provides details of overlap between two articles. The Erratum acknowledges that the 2007 article is cited in the 2012 article and clarifies the relationship between the two publications. As described in the Erratum, I reached the decision to issue a Correction after an evaluation during which I reviewed the COPE guidelines and gave consideration to the concerns raised by the author. While I regret not having identified the overlap prior to publication, primary responsibility for article content rests with the author.

\section{References}

COPE (2011) "Code of Conduct and Best Practice Guidelines for Journal Editors: 4. Relations with editors. Best practice for editors”. Publicationethics.org. COPE- Committee on Publication Ethics: 10 April 2012 http://publicationethics.org/files/Code_of_conduct_for_journal_editors_Mar11.pdf

COPE (2013) "What to do if you suspect redundant publication in a published article". Publicationethics.org. COPE- Committee on Publication Ethics: 28 Jan. 2012. http://publicationethics.org/files/u7140/ redundant $\% 20$ publication $\% 20$ B_0.pdf

David Vaux in Litt (2012) An independent, personal opinion on Dela 2007 and 2012 by a former member of the Committee on Freedom and Responsibility in the Conduct of Science (CFRS) of the International Council for Science (ICSU) with expertise in research integrity matters, and also an associate member of the Committee on Publication Ethics (COPE).

Davies, A. G., Oates, J. F., \& Dasilva, G. L. (1999). Patterns of frugivory in three West African Colobine monkeys. International Journal of Primatology, 20, 327-357.

Dela, J. (2007). Seasonal food use strategies of Semnopithecus vetulus nestor, at Panadura and Piliyandala, Sri Lanka. International Journal of Primatology, 28, 607-626.

Dela, J. (2012). Western purple-faced langurs (Semnopithecus vetulus nestor) feed on ripe and ripening fruit in human-modified environments in Sri Lanka. International Journal of Primatology, 33, 40-72.

Fashing, P. J., Dierenfeld, E. S., \& Mowry, C. B. (2007). Influence of plant and soil chemistry on food selection, ranging patterns, and biomass of Colobus guereza in Kakamega Forest, Kenya. International Journal of Primatology, 28(3), 673-703.

IJP (n.d.) "Guidelines for reviewers". Comments to the author on possible publication misconduct. Springer.com. International Journal of Primatology. 03 May 2014. http://www.springer.com/life+ sciences/evolutionary $+\% 26+$ developmental+biology/journal/10764?detailsPage=editorialBoard 
Li, Z., \& Rogers, M. E. (2006). Food items consumed by white-headed langurs in Fusui, China. International Journal of Primatology., 27(6), 1551-1567.

Setchell, J. S. (2012). Erratum to: Western Purple-Faced Langurs (Semnopithecus vetulus nestor) Feed on Ripe and Ripening Fruit in Human-Modified Environments in Sri Lanka. International Journal of Primatology, 33, 989-991.

Springer (2013) "Publishing Ethics for Journals. A guide for Editors-in-Chief, Associate Editors, and Managing Editors. 4.2 Duplicate submission/Publication and redundant publication." Version 1.0. http://static.springer.com/sgw/documents/1393202/application/pdf/Publication_Ethics_Guide_for_ Editors from Springer 27052013.pdf. Accessed 3 May 2014. 